\title{
Release Kinetic Studies of Stevia rebaudiana Extract Capsules from Sodium Alginate and Inulin by Ionotropic Gelation
}

\author{
Juan Pablo Quintal Martínez, ${ }^{1}$ Jorge Carlos Ruiz Ruiz $\mathbb{D i D}^{2}$ \\ and Maira Rubí Segura Campos $\mathbb{D}^{1}$ \\ ${ }^{1}$ Facultad de Ingeniería Química, Universidad Autónoma de Yucatán, Periférico Norte km. 33.5, Tablaje Catastral 13615, \\ Col. Chuburná de Hidalgo Inn, 97203 Mérida, YUC, Mexico \\ ${ }^{2}$ Escuela de Nutrición, Universidad Anáhuac Mayab, 97310 Mérida, YUC, Mexico
}

Correspondence should be addressed to Maira Rubí Segura Campos; maira.segura@correo.uady.mx

Received 9 February 2018; Revised 25 May 2018; Accepted 3 June 2018; Published 11 July 2018

Academic Editor: Michele Iafisco

Copyright $($ C 2018 Juan Pablo Quintal Martínez et al. This is an open access article distributed under the Creative Commons Attribution License, which permits unrestricted use, distribution, and reproduction in any medium, provided the original work is properly cited.

This study was oriented towards encapsulation of S. rebaudiana extract and the study of its release kinetics. The desired encapsulation was achieved by the ionotropic gelation method using sodium alginate and inulin of polymeric constituents. Characterization of the capsules was performed by micrometric properties, encapsulation efficiency, in vitro extract release analysis, and biological activity of released extract. The in vitro release profiles from different capsules were applied on different kinetic models. The prepared capsules were found spherical in shape with diameters ranging from 2.07 to $2.63 \mathrm{~mm}$, having the encapsulation efficiencies of $43.77 \%$ and $56.53 \%$ for phenolic compounds and steviol glycosides, respectively. The best-fit model with the highest correlation coefficient was observed in the Ritger-Peppas model, indicating diffusion controlled principle. The release exponent $n$ value obtained from the Korsmeyer-Peppas model varied between 0.2273 and 1.1719 , confirming that the mechanism of $S$. rebaudiana extract bioactive compounds release was diffusion controlled.

\section{Introduction}

The herbal-related products take into account herbs used as food or food additives, food supplements, traditional medicines, and so on. In addition, bioactive compounds of herbal plants such as antioxidants have shown to have multiple functional and remedial properties that include antiradical, anticarcinogenic, reduction of oxidative stress, anti-inflammatory, and cardio-protection [1]. From the standpoint of herbal products, encapsulation could achieve a number of desirable effects that includes controlled delivery, extending shelf life, separating incompatible compounds, and improving final product qualities [2].

Natural hydrophilic polymers, owing to their characteristic biocompatibility and biodegradability properties, are widely used in the pharmaceutical industry for the development of novel drug delivery systems. Alginate has been used in numerous biomedical applications, processed in various dosage forms, and used in sutures and dressing materials with characteristic features such as mucoadhesion, bioadhesion, and modifying drug release profile. Chemically, alginates are linear, anionic block copolymer heteropolysaccharides consisting of monomers of (-d-mannuronic acid) and its C-5 epimer (-1-guluronic acid), residues joined by 1,4 -glycosidic linkages [3].

The simple, mild, aqueous-based gel formation is achieved by the ionotropic gelling, on the addition of bivalent alkaline metals $\mathrm{Ca}^{2+}, \mathrm{Sr}^{2+}$, and $\mathrm{Ba}^{2+}$, due to an ionic interaction and intramolecular bonding between the carboxylic acid groups located on the polymer backbone and these cations. Calcium-induced alginate gel beads have been developed in recent years as a unique vehicle for the drug delivery system. These beads have been used in formulations as single or multiple units, with or without the addition of other hydrogels or polymers, intrapenetrating networks, nanospheres, polycations, and many more dosage forms for achieving temporal and spatial drug release [4]. 
In this study, an aqueous extract of $S$. rebaudiana Bertoni was used as the model herbal fluid. The effect of process variables (i.e., alginate concentration, cross-linking agent concentration, and cross-linking time) on encapsulation efficiency and micrometric properties was studied. The in vitro release profiles from capsules were applied on different kinetic models, and biological activity of extract after release was evaluated.

\section{Materials and Methods}

2.1. Raw Material and Chemicals. S. rebaudiana Bertoni variety Morita II was obtained from plots in the Yucatán State in Mexico. Samples were obtained from the first cut of the plot at an age of three months; samples consisted of branches of leaves. All chemicals were reagent grade or better and purchased from Sigma Chemical Co. (St. Louis, MO, USA).

2.2. S. rebaudiana Aqueous Extract Preparation. S. rebaudiana leaves were subjected to convection drying at $60^{\circ} \mathrm{C}$ for $24 \mathrm{~h}$. The leaves were milled to obtain particles of $1.0 \mathrm{~mm}$ in size. The extract was prepared by mixing one part of stevia leaves with nine parts of water. For such purpose, water was heated to $55^{\circ} \mathrm{C}$ and then mixed with stevia leaves, with the mixture being allowed to steep for 1 hour. After cooling, the extract was filtered through a paper filter and centrifuged at $3000 \mathrm{rpm}$ for $15 \mathrm{~min}$. The procedure was repeated twice more to achieve maximum extraction of steviol glycosides. The extract was stored in amber bottles and was refrigerated at $4^{\circ} \mathrm{C}$ until analysis [5].

\subsection{Quantification of Phytochemicals in S. rebaudiana Aqueous Extract}

2.3.1. Chlorophylls and Carotenoids. The extract absorbance was determined at $665,645,630$, and $444 \mathrm{~nm}$. The amounts of chlorophylls and carotenoids were calculated according to the equations reported by Lichtenthaller [6]:

$$
\begin{aligned}
\text { chlorophyll } \mathrm{a}(\mu \mathrm{g} / \mathrm{mL} \text { of extract })= & 11.6(A 665) \\
& -1.31(A 645) \\
& -0.14(A 630), \\
\text { chlorophyll } \mathrm{b}(\mu \mathrm{g} / \mathrm{mL} \text { of extract })= & -4.34(A 665) \\
& +20.7(A 645) \\
& -4.42(A 630), \\
\text { carotenoids }(\mu \mathrm{g} / \mathrm{mL} \text { of extract })= & 0.0051(A 444) \\
& +0.00003,
\end{aligned}
$$

where $A=$ absorbance determined at the different wavelengths $(665,645,630$, and $444 \mathrm{~nm})$.

2.3.2. Quantitative Phenolic Analysis. The phenolic compounds were determined using the Folin-Ciocalteu method [7]. Absorbance was determined at $760 \mathrm{~nm}$. The data were calculated by a comparison between a standard curve of gallic acid and the absorbance of each sample. The total amount of phenolic compounds was determined in milligrams of gallic acid equivalents/mg of sample. The flavonoid content was determined using the aluminum chloride method [8]. Absorbance was measured at $490 \mathrm{~nm}$. The data were calculated by a comparison between a standard curve $(0-100 \mu \mathrm{g} / \mathrm{mL}$ of catechin) and the absorbance of each sample. The total amount of flavonoid compounds was determined in milligrams of quercetin equivalents/mg of sample. Total flavonols were estimated as milligrams of naringenin equivalents/mg of sample. The absorbance was determined at $490 \mathrm{~nm}$ [9].

2.3.3. Quantification of Steviol Glycosides. Steviol glycosides were quantified by using the DNS (3,5-dinitrosalicylic acid) method. It is possible to correlate the content of steviol glycosides with the carbohydrate content [10]. The DNS method is based on the reduction of 3,5-dinitrosalicylic acid in the presence of glucose, which leads to 3-amino-5-salicylic whose maximum absorbance is at a wavelength of $570 \mathrm{~nm}$. A calibration curve was obtained with standard glucose concentrations in a range of concentrations from 0.0 to $1.2 \mathrm{mg} / \mathrm{mL}$.

\subsection{In Vitro Biological Activity of S. rebaudiana Aqueous Extract before and after Release}

2.4.1. Radical Scavenging Assay. The antiradical activity was evaluated using a dilution series to obtain five concentrations $(0.0-3.0 \mathrm{mg} / \mathrm{mL})$. This process involved mixing the $\mathrm{DPPH}$ solution $(60 \mathrm{mM}$ in ethanol) with an appropriate amount of the sample followed by homogenization. After $30 \mathrm{~min}$, the remaining $\mathrm{DPPH}$ radicals were quantified by measuring the absorption at $517 \mathrm{~nm}$. The percentage of inhibition was given by the following formula:

$$
\text { radical scavenging }(\%)=\left[\frac{\left(A_{0}-A_{1}\right)}{A_{0}}\right] \times 100 \text {, }
$$

where $A_{0}$ is the absorbance of the control solution and $A_{1}$ is the absorbance in the presence of the sample [11].

2.4.2. In Vitro $\alpha$-Amylase Inhibitory Assay. The assay was carried out following the standard protocol with slight modifications [12]. Starch (2 mg) was suspended in a tube containing $0.2 \mathrm{~mL}$ of $0.5 \mathrm{M}$ tris- $\mathrm{HCl}$ buffer ( $\mathrm{pH}$ 6.9) with $0.01 \mathrm{M}$ calcium chloride (substrate). The tube was boiled for $5 \mathrm{~min}$ and then preincubated at $37^{\circ} \mathrm{C}$ for $5 \mathrm{~min}$. Stevia aqueous extract $(10 \mathrm{mg} / \mathrm{mL})$ was dissolved with $1 \mathrm{~mL}$ of $0.1 \%$ of dimethyl sulfoxide in order to obtain a concentration of $400 \mu \mathrm{g} / \mathrm{mL}$. Then, $0.2 \mathrm{~mL}$ of stevia aqueous extract of a particular concentration was put in the tube containing the substrate solution. Then, $0.1 \mathrm{~mL}$ of porcine pancreatic amylase in tris- $\mathrm{HCl}$ buffer ( 2 units $/ \mathrm{mL}$ ) was added to the tube containing stevia aqueous extract and starch. The process was carried out at $37^{\circ} \mathrm{C}$ for $10 \mathrm{~min}$. The reaction was stopped by adding $0.5 \mathrm{~mL}$ of $50 \%$ acetic acid to each tube. The reaction mixture was then centrifuged at $2000 \times \mathrm{g}$ for $5 \mathrm{~min}$ at $4^{\circ} \mathrm{C}$. 
The absorbance of the resulting supernatant was measured at $595 \mathrm{~nm}$ using a spectrophotometer. The $\alpha$-amylase inhibitory activity was calculated as follows:

$$
\alpha \text {-amylase inhibition }(\%)=\frac{\left(A_{\mathrm{c}^{+}}\right)-\left(A_{\mathrm{c}^{-}}\right)-\left(A_{\mathrm{s}}-A_{\mathrm{b}}\right)}{\left(A_{\mathrm{c}^{+}}\right)-\left(A_{\mathrm{c}^{-}}\right)} \times 100 \text {, }
$$

where $A_{\mathrm{c}^{+}}=100 \%$ enzyme activity (only solvent with enzyme). $A_{c^{-}}=0 \%$ enzyme activity (only solvent without enzyme). $A_{\mathrm{s}}=$ test sample (with enzyme). $A_{\mathrm{b}}=$ blank (test sample without enzyme).

2.4.3. ACE Inhibitory Activity. Angiotensin-converting enzyme (ACE) inhibitory activity in samples was determined following the study of Hayakari et al. [13]. Hippuryl-L-histidyl-L-leucine (HHL) is hydrolyzed by ACE to yield hippuric acid and histidylleucine. This method relies on the colorimetric reaction of hippuric acid with 2,4,6-trichloro-s-triazine (TT) in a $0.5 \mathrm{~mL}$ incubation mixture containing $40 \mu \mathrm{mol}$ potassium phosphate buffer $(\mathrm{pH}$ 8.3), $300 \mu \mathrm{mol}$ sodium chloride, $40 \mu \mathrm{mol} 3 \%$ HHL in po-

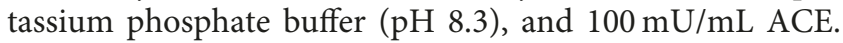
The mixture was incubated at $37^{\circ} \mathrm{C}$ for $45 \mathrm{~min}$, and the reaction terminated by adding $\mathrm{TT}(3 \% \mathrm{v} / \mathrm{v})$ in dioxane and $3 \mathrm{~mL}$ of $0.2 \mathrm{M}$ potassium phosphate buffer $(\mathrm{pH} 8.3)$. After centrifuging the reaction mixture at $10,000 \times \mathrm{g}$ for $10 \mathrm{~min}$, the enzymatic activity was determined in the supernatant by measuring absorbance $(A)$ at $382 \mathrm{~nm}$. The ACE inhibitory activity (\%) was calculated using the following formula:

$$
\operatorname{ACE} \text { inhibition }(\%)=\frac{(A-B)}{(A-C)} \times 100
$$

where $A=$ sample $+\mathrm{HHL}+$ enzyme, $B=\mathrm{HHL}+$ enzyme, and $C=\mathrm{HHL}+$ enzyme + inactivator.

2.5. Preparation of S. rebaudiana Extract Capsules. A $3^{2}$ factorial model with four central treatments was used to evaluate the extract encapsulation conditions. The evaluated factors and levels were alginate concentration ( 2 and $4 \%, \mathrm{w} / \mathrm{v}$ ), cross-linking agent concentration ( 6 and 10\%, w/v), and crosslinking time (10 and $30 \mathrm{~min})$. Response variables included encapsulation efficiency of phenolic compounds and steviol glycosides. Polymer solutions were obtained by dissolving sodium alginate in deionized water and magnetic stirring for $24 \mathrm{~h}$. Then, $50 \mathrm{~mL}$ of alginate solution was pumped at a flow rate of $10.0 \mathrm{~mL} / \mathrm{min}$ using a peristaltic pump with a hose ( $2 \mathrm{~mm}$ internal diameter) to an eight-nozzle dispensing disc and dropped into a solution of calcium chloride. The disc was fitted with eight polyethylene helical-thread tapered tips (1.4 mm internal diameter). The calcium chloride solution was stirred at $400 \mathrm{rpm}$ with an $80 \mathrm{~mm}$ long wedge-shaped magnetic bar. The beads formed were cured at room temperature; wet capsules were washed with demineralised water. Finally, the capsules were stored at $4^{\circ} \mathrm{C}$ until further use.

2.6. Encapsulation Efficiency. Encapsulation efficiency (EE\%) was calculated as the amount of phenolic compounds and steviol glycosides encapsulated in beads $(b)$ divided by the phenolic compounds and steviol glycosides of the solution used for the preparation of beads $(s)$, as shown in the following equation:

$$
\mathrm{EE} \%=\frac{b}{s} \times 100
$$

Quantification of phenolic compounds and steviol glycosides in beads was performed after dissolving beads in $2 \%$ (w/v) Na-citrate solution (at a weight ratio of $1: 5$ ), using a Vortex mixer to chemically dissolve them at room temperature. Phenolic compounds and steviol glycosides were determined using the methods previously described.

\subsection{Micrometric Properties}

2.7.1. Bead Diameter. Maximum and minimum diameters of beads from different encapsulation treatments were measured using a caliper with an accuracy of $0.01 \mathrm{~mm} \mathrm{[3].}$

2.7.2. Sphericity Factor. The sphericity factor (SF) was selected as the criterion to quantify the sphericity of the capsules [14]. The SF is defined as

$$
\mathrm{SF}=\frac{\left(d_{\max }-d_{\min }\right)}{\left(d_{\max }+d_{\min }\right)}
$$

where $d_{\max }=$ maximum diameter and $d_{\min }=$ minimum diameter perpendicular to $d_{\max }$.

2.7.3. Bulk and Tapped Densities. Bulk and tapped densities were measured by using a $10 \mathrm{~mL}$ graduated cylinder. The sample poured into the cylinder was tapped mechanically for 100 times, and then, the tapped volume was noted down. Bulk density and tapped density were calculated [3].

2.7.4. Carr's Index. The compressibility index value of capsules was calculated according to the following equation [3]:

Carr's index $(\%)=\frac{(\text { tapped density }- \text { bulk density })}{\text { tapped density }} \times 100$.

2.7.5. Hausner's Ratio. Hausner's ratio of capsules was determined by comparing the tapped density to the bulk density using the following equation [3]:

$$
\text { Hausner's ratio }=\frac{\text { tapped density }}{\text { bulk density }} \text {. }
$$

2.8. In Vitro S. rebaudiana Extract Release Studies. The content of extract released from beads was determined by sinking a known amount of capsules in the release media while agitating at $125 \mathrm{rpm}$. The release media used were in vitro model digestion fluids: simulated gastrointestinal fluid, 
TABLE 1: Encapsulation efficiency of phenolic compounds and steviol glycosides as response variables of encapsulation factors and levels.

\begin{tabular}{lccccc}
\hline Treatment & $\begin{array}{c}\text { Alginate } \\
\text { concentration } \\
(\%, \mathrm{w} / \mathrm{v})\end{array}$ & $\begin{array}{c}\mathrm{CaCl}_{2} \\
\text { concentration } \\
(\%, \mathrm{w} / \mathrm{v})\end{array}$ & $\begin{array}{c}\text { Cross-linking } \\
\text { time } \\
(\mathrm{min})\end{array}$ & $\begin{array}{c}\text { Encapsulation efficiency } \\
\text { of phenolic } \\
\text { compounds (\%) }\end{array}$ & $\begin{array}{c}\text { Encapsulation efficiency } \\
\text { of steviol } \\
\text { glycosides (\%) }\end{array}$ \\
\hline 1 & 2 & 6 & 10 & 43.54 & 49.95 \\
2 & 4 & 6 & 10 & 42.84 & 56.53 \\
3 & 2 & 10 & 10 & 42.03 & 37.80 \\
4 & 4 & 10 & 10 & 39.48 & 36.53 \\
5 & 2 & 6 & 30 & 43.77 & 50.44 \\
6 & 4 & 6 & 30 & 41.76 & 50.92 \\
7 & 2 & 10 & 30 & 42.44 & 34.63 \\
8 & 4 & 10 & 30 & 33.64 & 34.00 \\
CT & 3 & 8 & 20 & 40.33 & 54.30 \\
\hline
\end{tabular}

$\mathrm{CT}=$ central treatment.

SGF $\left(3 \mathrm{~h}\right.$ at $\left.37^{\circ} \mathrm{C}\right)$, followed by immersion in simulated intestinal fluid, SIF ( $3 \mathrm{~h}$ at $37^{\circ} \mathrm{C}$ ). SGF was prepared from a solution of hydrochloric acid $0.1 \mathrm{M}$ corrected with sodium hydroxide to $\mathrm{pH}=2$, and SIF from phosphate buffer $(\mathrm{pH}$ 7.5). The amount of extract released, determined as phenolic content and steviol glycosides content, was calculated with the following equation:

$$
\text { Extract released }(\%)=\frac{E}{E_{\mathrm{o}}} \times 100,
$$

where $E$ is the amount of extract determined in the release medium and $E_{\mathrm{o}}$ is the initial amount of extract in the capsules. $E_{\mathrm{o}}$ for each type of capsule corresponded to the mass of phenolic compounds and steviol glycosides detected after capsule disintegration [2]. In order to investigate the mode of release from microcapsules, the release data were analyzed using following mathematical models: zero-order kinetic, firstorder kinetic, Higuchi equation [15], Korsmeyer-Peppas equation [16], and Ritger and Peppas [17]:

$$
\begin{gathered}
\text { Zero-order }=Q=k_{0} t, \\
\text { First-order }=\ln (100-Q)=\ln \left(Q_{0}\right)-k_{1} t, \\
\text { Higuchi }=Q=k_{\mathrm{H}} t^{(1 / 2)}, \\
\text { Korsmeyer-Peppas }=\log \left(\frac{Q}{100}\right)=k_{\mathrm{P}} t n, \\
\text { Ritger-Peppas }=\log \left(\frac{Q_{0}}{Q}\right)=\log k+n \log t .
\end{gathered}
$$

where $Q$ is the percent of extract released at time $t, Q_{0}$ is the percent of extract remaining to release, and $k_{0}, k_{1}$, and $k_{\mathrm{H}}$ are the coefficients of the equations. $k_{\mathrm{P}}$ and $k_{\mathrm{R}}$ are the constants that incorporating structural and geometric characteristics of capsule, and $n$ is the release exponent indicative of the mechanism of release. The experiments to determine the release kinetics were carried out in triplicate.

\section{Results and Discussion}

3.1. Quantification of Phytochemicals in S. rebaudiana Aqueous Extract. Contents of chlorophylls a and b were 15.35 and $16.53 \mu \mathrm{g} / \mathrm{mL}$ of extract, respectively. For carotenoids, the content was $0.029 \mu \mathrm{g} / \mathrm{mL}$ of extract. The content of phenolic compounds, flavonoids, and flavonols were $75.87 \mathrm{mg}$ equivalents of gallic acid $/ \mathrm{mL}$ of extract, $153.63 \mathrm{mg}$ equivalents of catechin/mL of extract, and $62.64 \mathrm{mg}$ equivalents of naringenin $/ \mathrm{mL}$ of extract, respectively. For steviol glycosides, the content was $3.18 \mathrm{mg} / \mathrm{mL}$ of extract. The results indicate that the aqueous extract of $S$. rebaudiana contains several types of phytochemicals, which have the capacity to exert different types of biological activity.

3.2. Encapsulation Efficiency. The effect of alginate concentration, cross-linking agent concentration, and cross-linking time on the encapsulation efficiency of S. rebaudiana phenolic compounds and steviol glycosides is shown in Table 1. The encapsulation efficiency was determined immediately after the encapsulation process. Alginate concentration and cross-linking agent concentration significantly influence the encapsulation efficiency of phenolic compounds $\left(\mathrm{EE}_{\mathrm{PC}}\right)$ $(p>0.05)$, with a negative effect. $\mathrm{EE}_{\mathrm{PC}}$ was expressed as percentage and ranging from 33.64 to $43.77 \%$. For the encapsulation efficiency of steviol glycosides ( $\left.E_{\mathrm{SG}}\right)$, only alginate concentration significantly influences the encapsulation efficiency $(p>0.05)$, with a negative effect. $\mathrm{EE}_{\mathrm{SG}}$ was expressed as percentage and ranging from 34.00 to $56.53 \%$.

In the present study, higher concentrations of alginate concentration and cross-linking agent reduced the encapsulation efficiency of phenolic compounds and steviol glycosides. With respect to the cross-linking time, this variable did not have a significant effect on the encapsulation efficiency. According to Kamaruddin et al. [18] during formation of capsules at higher concentrations of alginate and cross-linking agent, a stiff gel is quickly generated which can promote the release of encapsulated material from the core. The inclusion of $2 \%(\mathrm{w} / \mathrm{w})$ of inulin in all treatments increased the encapsulation efficiency by the reduction of pore size of alginate beads in the presence of the filler (inulin), which prevented the leakage of the encapsulated compounds [19]. With treatment 2 , the encapsulation efficiency was high for both phenolic compounds and steviol glycosides, simultaneously.

3.3. Micrometric Properties. The knowledge and control of the size of particles are of importance in pharmacy and 
TABLE 2: Micromeretic properties of beads as response variables of encapsulation treatments.

\begin{tabular}{lcccccc}
\hline Treatment & $\begin{array}{c}\text { Diameter } \\
(\mathrm{mm})\end{array}$ & $\begin{array}{c}\text { Sphericity factor } \\
(\text { dimensionless })\end{array}$ & $\begin{array}{c}\text { Bulk density } \\
\left(\mathrm{mg} / \mathrm{cm}^{3}\right)\end{array}$ & $\begin{array}{c}\text { Tapped density } \\
\left(\mathrm{mg} / \mathrm{cm}^{3}\right)\end{array}$ & $\begin{array}{c}\text { Compressibility index }(\%) \\
(\mathrm{dimensionless})\end{array}$ \\
\hline 1 & $2.07 \pm 0.172$ & $0.0585 \pm 0.0325$ & $726.46 \pm 26.554$ & $958.33 \pm 36.084$ & $24.18 \pm 1.949$ & $1.32 \pm 0.033$ \\
2 & $2.52 \pm 0.155$ & $0.0408 \pm 0.032$ & $667.55 \pm 29.698$ & $849.67 \pm 28.301$ & $21.44 \pm 1.759$ & $1.27 \pm 0.028$ \\
3 & $2.43 \pm 0.206$ & $0.0407 \pm 0.030$ & $669.43 \pm 53.929$ & $884.40 \pm 0.0527$ & $24.34 \pm 2.966$ & $1.32 \pm 0.052$ \\
4 & $2.69 \pm 0.169$ & $0.0259 \pm 0.019$ & $697.93 \pm 16.235$ & $835.05 \pm 46.463$ & $16.29 \pm 4.056$ & $1.20 \pm 0.056$ \\
5 & $2.61 \pm 0.167$ & $0.0424 \pm 0.033$ & $692.88 \pm 24.169$ & $891.77 \pm 29.992$ & $22.23 \pm 4.090$ & $1.29 \pm 0.068$ \\
6 & $2.63 \pm 0.142$ & $0.0216 \pm 0.0155$ & $620.93 \pm 15.041$ & $759.24 \pm 57.226$ & $17.92 \pm 6.171$ & $1.22 \pm 0.093$ \\
7 & $2.20 \pm 0.181$ & $0.0573 \pm 0.036$ & $714.56 \pm 17.018$ & $938.11 \pm 29.330$ & $23.82 \pm 0.567$ & $1.31 \pm 0.009$ \\
8 & $2.46 \pm 0.094$ & $0.0248 \pm 0.017$ & $743.90 \pm 10.561$ & $857.61 \pm 24.513$ & $13.23 \pm 1.538$ & $1.15 \pm 0.020$ \\
CT & $2.46 \pm 0.162$ & $0.0282 \pm 0.002$ & $635.55 \pm 56.367$ & $832.21 \pm 21.259$ & $21.52 \pm 5.194$ & $1.28 \pm 0.080$ \\
\hline
\end{tabular}

$\mathrm{CT}=$ central treatment.

TABLE 3: In vitro phenolic compounds and steviol glycosides release studies.

\begin{tabular}{lcrrr}
\hline Treatment & $\begin{array}{c}\text { Phenolic compounds (\%) } \\
\text { Simulated gastric fluid }\end{array}$ & $\begin{array}{c}\text { Steviol glycosides (\%) } \\
\text { Simulated intestinal fluid }\end{array}$ & $\begin{array}{c}\text { Phenolic compounds (\%) } \\
\text { Simules (\%) }\end{array}$ \\
\hline 1 & $64.10 \pm 1.28$ & $58.00 \pm 1.16$ & $35.90 \pm 0.72$ & $42.00 \pm 0.84$ \\
2 & $58.46 \pm 1.16$ & $45.43 \pm 0.91$ & $41.54 \pm 0.83$ & $54.57 \pm 1.09$ \\
3 & $63.32 \pm 1.26$ & $58.29 \pm 1.16$ & $36.68 \pm 0.73$ & $41.71 \pm 0.83$ \\
4 & $63.39 \pm 1.27$ & $48.06 \pm 0.96$ & $36.61 \pm 0.69$ & $51.94 \pm 1.04$ \\
5 & $66.82 \pm 1.37$ & $82.58 \pm 1.65$ & $33.18 \pm 0.66$ & $17.42 \pm 0.35$ \\
6 & $62.62 \pm 1.25$ & $47.18 \pm 0.94$ & $37.38 \pm 0.75$ & $52.82 \pm 1.06$ \\
7 & $63.99 \pm 1.22$ & $30.80 \pm 0.55$ & $36.01 \pm 0.72$ & $69.20 \pm 1.38$ \\
8 & $57.92 \pm 1.16$ & $11.92 \pm 0.28$ & $42.08 \pm 0.91$ & $88.08 \pm 2.21$ \\
CT & $63.48 \pm 1.21$ & $31.22 \pm 0.72$ & $36.52 \pm 0.71$ & $68.78 \pm 1.38$ \\
\hline
\end{tabular}

$\mathrm{CT}=$ central treatment.

materials science. The size, and hence the surface area of a particle, can be related to the physical, chemical, and pharmacologic properties. Clinically, the particle size can affect its release from dosage forms that are administered orally, parenterally, rectally, and topically [20]. Micrometric properties are shown in Table 2.

The various treatments have the average diameter in the range of $2.07-2.69 \mathrm{~mm}$. The sphericity factor (SF) ranged from 0.0216 to 0.0585 ; $\mathrm{SF}$ is a dimensionless shape indicator, and this varies from 0 for a perfect sphere to approaching unity for an elongated object. The obtained values indicate that the alginate-inulin capsules have a predominantly spherical shape. For these properties, only alginate concentration significantly influenced $(p>0.05)$, with a positive effect. In this sense, a higher polymer (alginate-inulin) concentration allows a better distribution of the polymer around the material to be encapsulated, increasing the size of the capsule and improving its shape during dripping prior to cross-linking. The bulk density value ranged from 620.93 to $726.46 \mathrm{mg} / \mathrm{cm}^{3}$, and tapped density varied in the range of $759.24-958.33 \mathrm{~g} / \mathrm{cm}^{3}$. For these properties, only alginate concentration significantly influenced $(p>0.05)$, with a negative effect. A higher polymer (alginate-inulin) concentration reduces the amount of material to be encapsulated retained in the capsule, and this therefore reduces the final density of the capsules, since their content is lower. The compressibility index was between 13.23 and $24.34 \%$, and Hausner's ratio was in the range from 1.15 to 1.32 . For these properties, no factor significantly influenced $(p>0.05)$.
These micromeritic properties indicate that the prepared capsules were spherical, nonaggregated, and uniform in size.

3.4. In Vitro S. rebaudiana Extract Release Studies. S. rebaudiana extract release from the capsules was studied at a $\mathrm{pH}$ of 2 for $3 \mathrm{~h}$ followed by phosphate buffer at a $\mathrm{pH}$ of 7.5 for $3 \mathrm{~h}$. The release percentages of phenolic compounds and steviol glycosides are shown in Table 3 . The result revealed that phenolic compounds release in SGF at a pH of 2 ranged from 57.92 to $66.82 \%$. After gastric conditions, phenolic compounds release in SIF at a $\mathrm{pH}$ of 7.5 ranged from 33.18 to 42.08\%. Steviol glycosides' release in SGF ranged from 11.92 to $82.58 \%$. Release in SIF ranged from 17.42 to $88.08 \%$.

For the release kinetics of the phenolic compounds evaluated through the zero-order model, the correlation coefficients oscillated between 0.8213 and 0.9631 (Table 4), indicating an adequate adjustment of the data to the kinetic model. The velocity constants ranged between 17.6587 and 27.0733. For the first-order model, the correlation coefficients oscillated between 0.6920 and 0.9612 . The constants ranged from 0.1960 to 0.8047 . Capsules obtained at low concentrations of the cross-linking agent $(6 \% \mathrm{w} / \mathrm{v})$ slowly released their contents. Encapsulation treatments presented a better fit with the Higuchi, Korsmeyer-Peppas, and Ritger-Peppas models. The Higuchi model indicates that the released compound will flow unidirectional from the encapsulating matrix to the release medium (Fick diffusion). The Korsmeyer-Peppas and Ritger-Peppas models applied 
TABle 4: Constant $(K)$, correlation coefficient $\left(r^{2}\right)$, and release exponent $(n)$ of different kinetic models for phenolic compounds release.

\begin{tabular}{|c|c|c|c|c|c|c|c|c|c|c|c|}
\hline \multirow[t]{2}{*}{ Treatment } & \multicolumn{2}{|c|}{ Zero-order } & \multicolumn{2}{|c|}{ First-order } & \multicolumn{2}{|c|}{ Higuchi equation } & \multicolumn{2}{|c|}{$\begin{array}{c}\text { Korsmeyer- } \\
\text { Peppas equation }\end{array}$} & \multicolumn{2}{|c|}{$\begin{array}{l}\text { Ritger-Peppas } \\
\text { equation }\end{array}$} & \multirow{2}{*}{$\begin{array}{c}\text { Release exponent } \\
n \\
\end{array}$} \\
\hline & $K_{0}$ & $r^{2}$ & $K_{1}$ & $r^{2}$ & $K_{\mathrm{H}}$ & $r^{2}$ & $K_{\mathrm{P}}$ & $r^{2}$ & $K_{\mathrm{R}}$ & $r^{2}$ & \\
\hline 1 & 25.2887 & 0.9337 & 0.1960 & 0.8450 & 43.4997 & 0.9650 & 71.4719 & 0.9391 & 86.3898 & 0.9508 & 0.3190 \\
\hline 2 & 24.3787 & 0.9452 & 0.2460 & 0.9291 & 43.0789 & 0.9831 & 74.4419 & 0.9309 & 96.3699 & 0.9088 & 0.2879 \\
\hline 3 & 28.7888 & 0.9631 & 0.5000 & 0.9415 & 45.3245 & 0.9204 & 66.6062 & 0.6756 & 75.8300 & 0.9478 & 0.2375 \\
\hline 4 & 23.2425 & 0.8657 & 0.3035 & 0.7972 & 40.2989 & 0.9135 & 78.9730 & 0.9727 & 99.4612 & 0.9298 & 0.2401 \\
\hline 5 & 27.0733 & 0.8213 & 0.8047 & 0.6920 & 49.4520 & 0.9556 & 73.0955 & 0.8885 & 93.6617 & 0.9751 & 0.2970 \\
\hline 6 & 17.6587 & 0.9456 & 0.2947 & 0.8408 & 32.9570 & 0.9215 & 73.3700 & 0.9876 & 73.4030 & 0.9567 & 0.2761 \\
\hline 7 & 23.8869 & 0.9073 & 0.3038 & 0.9612 & 40.5374 & 0.9478 & 73.7973 & 0.8028 & 98.7855 & 0.9294 & 0.2273 \\
\hline 8 & 26.6136 & 0.9607 & 0.2494 & 0.7509 & 42.4097 & 0.9306 & 68.7520 & 0.8227 & 78.6048 & 0.9209 & 0.2866 \\
\hline $\mathrm{CT}$ & 20.5049 & 0.9225 & 0.6274 & 0.8867 & 38.3798 & 0.9722 & 76.5501 & 0.9759 & 86.9574 & 0.9399 & 0.2454 \\
\hline
\end{tabular}

CT=central treatment.

TABLE 5: Constant $(K)$, correlation coefficient $\left(r^{2}\right)$, and release exponent $(n)$ of different kinetic models for steviol glycosides release.

\begin{tabular}{|c|c|c|c|c|c|c|c|c|c|c|c|}
\hline \multirow[t]{2}{*}{ Treatment } & \multicolumn{2}{|c|}{ Zero-order } & \multicolumn{2}{|c|}{ First-order } & \multicolumn{2}{|c|}{ Higuchi equation } & \multicolumn{2}{|c|}{$\begin{array}{c}\text { Korsmeyer- } \\
\text { Peppas equation }\end{array}$} & \multicolumn{2}{|c|}{$\begin{array}{l}\text { Ritger-Peppas } \\
\text { equation }\end{array}$} & \multirow{2}{*}{$\begin{array}{c}\text { Release exponent } \\
n\end{array}$} \\
\hline & $K_{0}$ & $r^{2}$ & $K_{1}$ & $r^{2}$ & $K_{\mathrm{H}}$ & $r^{2}$ & $K_{\mathrm{P}}$ & $r^{2}$ & $K_{\mathrm{R}}$ & $r^{2}$ & \\
\hline 1 & 35.1638 & 0.9203 & 0.4096 & 0.9241 & 60.1849 & 0.9418 & 49.8865 & 0.7855 & 24.5906 & 0.9580 & 0.5278 \\
\hline 2 & 28.0270 & 0.9998 & 0.1563 & 0.9242 & 46.6406 & 0.9223 & 65.2063 & 0.9870 & 45.5452 & 0.9006 & 0.4444 \\
\hline 3 & 26.6233 & 0.9327 & 0.1160 & 0.9206 & 45.8626 & 0.9920 & 71.5522 & 0.9914 & 52.5268 & 0.9311 & 0.3601 \\
\hline 4 & 29.4402 & 0.9963 & 0.1523 & 0.8843 & 49.6953 & 0.9457 & 58.5737 & 0.8605 & 42.6789 & 0.9497 & 0.4266 \\
\hline 5 & 27.2709 & 0.9906 & 0.8853 & 0.9908 & 41.9192 & 0.9638 & 57.6390 & 0.9696 & 54.7285 & 0.9813 & 0.4148 \\
\hline 6 & 19.0412 & 0.9389 & 0.5999 & 0.8701 & 41.0342 & 0.9242 & 49.1339 & 0.8877 & 45.7341 & 0.9614 & 0.4869 \\
\hline 7 & 14.0117 & 0.9590 & 0.1508 & 0.9727 & 52.8596 & 0.8553 & 20.7832 & 0.9210 & -7.1407 & 0.9307 & 0.7312 \\
\hline 8 & 37.9265 & 0.9951 & 1.1922 & 0.9888 & 58.0884 & 1.0000 & 25.1194 & 0.9912 & -67.9237 & 0.8441 & 1.6428 \\
\hline $\mathrm{CT}$ & 29.8113 & 0.9242 & 0.5946 & 0.9539 & 64.6968 & 0.9588 & 37.0361 & 0.9356 & -8.5843 & 0.9515 & 1.1719 \\
\hline
\end{tabular}

$\mathrm{CT}=$ central treatment.

to the release data of the phenolic compounds indicated that the faster release rate constants were observed for treatment 4 (Table 4 ). In the case of the values of the exponent $n$, these were less than 0.5 , indicating again a liberation of the Fickian type. The values of the exponents also indicate that the geometry of the capsules is very close to sphericity.

In general, in all the kinetic models, the decrease in the release rate was observed with the increase in alginate concentration. In this sense, Kikuchi et al. [21] observed that the mechanism of release of compounds from alginate capsules showed a behavior dependent on molecular weight. These researchers concluded that a low molecular weight compound follows a mechanism of the Fickian diffusion through the encapsulating polymer. Similarly, BelscakCvitanovic et al. [22] conducted a study on the release of phenolic compounds from various plants and observed that all the release profiles conformed to the Fickian diffusion model. Taking these two studies into account, it can be pointed out that phenolic compounds, having a low molecular weight, can easily permeate through the capsules and cannot interact through adsorption or ionic interaction with the encapsulating polymeric material [23].

The data obtained from the release kinetics of steviol glycosides were mainly adjusted to the zero-order and the Higuchi models (Table 5). The zero-order model indicated that the swelling of the polymer chains controlled the release process. Migration of the steviol glycosides to the medium implied a process of absorption of water and simultaneous desorption of the bioactive compound. Data also were studied applying the Korsmeyer-Peppas and Ritger-Peppas models; in this case, the values of $n$ oscillated between 0.45 and 0.89 . This indicates that the release of steviol glycosides from the capsules followed the transport mechanism of Case II or anomalous due to rapid swelling, capsule erosion, and diffusion of steviol glycosides.

The steviol glycosides have a higher molecular weight than the phenolic compounds, and the values of the constants $(K)$ were lower; this means that steviol glycosides are released slower due to their interaction with the polymer membrane [23].

3.5. In Vitro Biological Activity of S. rebaudiana Aqueous Extract before and after Release. In vitro assays of biological activity were carried out at an extract concentration of $0.4 \mathrm{mg} / \mathrm{mL}$. For radical scavenging, the extract had the capacity to capture $30.06 \%$ of the DPPH-free radicals present in the test reaction medium. In the antidiabetic assay, the extract inhibited the activity of the $\alpha$-amylase enzyme by $20.36 \%$. For antihypertensive activity, the extract had the ability to inhibit $26.03 \%$ of the activity of angiotensin converting enzyme. The $S$. rebaudiana extract has the capacity to present several biological activities, due to its content of phytochemicals. Chlorophylls possess antioxidant 
TABLE 6: Biological activity of encapsulated S. rebaudiana extract after release simulation.

\begin{tabular}{lccc}
\hline Treatment & Radical scavenging (\%) & $\alpha$-amylase inhibition (\%) & Angiotensin I converting enzyme inhibition (\%) \\
\hline 1 & $48.11^{\mathrm{c}}$ & $48.64^{\mathrm{bc}}$ & $52.43^{\mathrm{cde}}$ \\
2 & $52.18^{\mathrm{a}}$ & $46.20^{\mathrm{c}}$ & $53.68^{\mathrm{bcde}}$ \\
3 & $50.00^{\mathrm{bc}}$ & $48.64^{\mathrm{bc}}$ & $42.82^{\mathrm{e}}$ \\
4 & $50.52^{\mathrm{ab}}$ & $44.91^{\mathrm{c}}$ & $63.36^{\mathrm{abc}}$ \\
5 & $50.49^{\mathrm{ab}}$ & $45.36^{\mathrm{c}}$ & $57.36^{\mathrm{abcd}}$ \\
6 & $51.49^{\mathrm{ab}}$ & $46.03^{\mathrm{c}}$ & $46.64^{\mathrm{de}}$ \\
7 & $51.52^{\mathrm{ab}}$ & $56.91^{\mathrm{a}}$ & $58.18^{\mathrm{abcd}}$ \\
8 & $50.40^{\mathrm{ab}}$ & $52.44^{\mathrm{ab}}$ & $69.72^{\mathrm{a}}$ \\
CT & $49.80^{\mathrm{bc}}$ & $55.22^{\mathrm{a}}$ & $66.04^{\mathrm{ab}}$ \\
\hline
\end{tabular}

Different superscripts indicate statistical significance. $\mathrm{CT}=$ central treatment.

activity by breaking the radical chain reaction, and carotenoids react with radical species by electron transfer, hydrogen abstraction, and the addition of a radical species $[24,25]$. Phenolic compounds can prevent disease through mechanisms that differ from antioxidant function, such as cellular signaling, gene expression, and modulation of enzymatic activity [26]. Many plant glycosides have shown activity in cancer prevention, as well as antidiabetic, antiobesity, antibacterial, or antineoplastic effect, and so on [27].

Biological activity of $S$. rebaudiana aqueous extract after release is shown in Table 6. Radical scavenging ranged from 48.11 to $52.18 \%$. Inhibition of $\alpha$-amylase enzyme ranged from 44.91 to $56.91 \%$. Angiotensin-converting enzyme inhibition ranged from 42.82 to $69.72 \%$. Biological activity was greater prior to encapsulation. During encapsulation process, high molecular weight compounds such as chlorophyll, carotenoid, and xanthophyll pigments, as well as colloidal particles and residues of plant material, may have been excluded from the encapsulated matrix. In this way, phenolic compounds and steviol glycosides mostly constituted the encapsulated matrix. The biological activity of both types of compounds could be increased due to the reduction of the interfering effect of the other components of the plant extract.

In the present study, encapsulation allowed to retain the most biologically active fraction of the $S$. rebaudiana aqueous extract. The increase in the concentrations of alginate and cross-linking agent resulted in a more rigid barrier, which allowed the greater protection of the phytochemical compounds and consequently a greater biological activity.

\section{Conclusions}

It can be concluded that capsules of sodium alginate and inulin obtained by ionotropic gelation are a reproducible and simple method for the preparation of $S$. rebaudiana aqueous extract capsules. It was found that the prepared capsules were spherical, good encapsulation percentage efficiency, and high yielding capacity. It can be concluded from this study that $S$. rebaudiana aqueous extract capsules could be made suitable for oral controlled drug delivery systems. However, the in vitro release characteristics of phenolic compounds and steviol glycosides from the encapsulated extract are subject to confirmation in animal and human studies for concluding enhanced bioavailability and dose frequency.

\section{Data Availability}

The data used to support the findings of this study are available from the corresponding author upon request.

\section{Conflicts of Interest}

The authors declare that there are no conflicts of interest regarding the publication of this paper.

\section{References}

[1] P. M. Kris-Etherton, M. Lefevre, G. R. Beecher, M. D. Gross, C. L. Keen, and T. D. Etherton, "Bioactive compounds in nutrition and health-research methodologies for establishing biological function: the antioxidant and anti-inflammatory effects of flavonoids on atherosclerosis," Annual Review of Nutrition, vol. 24, no. 1, pp. 511-538, 2004.

[2] L. Deladino, P. S. Anbinder, A. S. Navarro, and M. N. Martino, "Encapsulation of natural antioxidants extracted from Ilex paraguariensis," Carbohydrate Polymer, vol. 71, no. 1, pp. 126-134, 2008.

[3] K. Asha, V. Dash, and B. C. Maiti, "Formulation and evaluation of calcium alginate beads from plant extract," Indian Journal of Novel Drug Delivery, vol. 3, no. 3, pp. 197-205, 2011.

[4] Y. L. Patel, P. Sher, and A. P. Pawar, "The effect of drug concentration and curing time on processing and properties of calcium alginate beads containing metronidazole by response surface methodology," AAPS Pharmaceutical Science and Technology, vol. 7, no. 4, pp. E1-E7, 2006.

[5] J. C. Ruiz-Ruiz, Y. B. Moguel-Ordoñez, A. J. Matus-Basto, and M. R. Segura-Campos, "Nutritional, amylolytic enzymes inhibition and antioxidant properties of bread incorporated with Stevia rebaudiana," International Journal of Food Science and Nutrition, vol. 66, no. 6, pp. 649-656, 2015.

[6] H. K. Lichtenthaller, "Chlorophylls and carotenoids, pigments of photosynthetic biomembranes," Methods in Enzymology, vol. 148 , pp. 350-382, 1987.

[7] S. Georgé, P. Brat, P. Alter, and M. Amiot, "Rapid determination of polyphenols and vitamin $\mathrm{C}$ in plant-derived products," Journal of Agricultural and Food Chemistry, vol. 53, no. 5, pp. 1370-1373, 2005.

[8] K. Lee, Y. Kim, H. Lee, and C. Lee, "Cocoa has more phenolic phytochemicals and a higher antioxidant capacity than teas and red wine," Journal of Agricultural and Food Chemistry, vol. 51, no. 25, pp. 7292-7295, 2003. 
[9] M. Popova, S. Silici, O. Kaftanoglu, and V. Bankova, “Antibacterial activity of Turkish propolis and its qualitative and quantitative chemical composition," Phytomedicine, vol. 12, no. 3, pp. 221-228, 2005.

[10] P. Nishiyama, I. T. Kusumoto, S. C. Costa, M. Alvarez, and L. G. Vieira, "Correlation between the contents of total carbohydrates and steviosides in leaves of Stevia rebaudiana," Arquivos de Biologia e Tecnologia, vol. 34, no. 3-4, pp. 425434, 1991.

[11] T. M. S. Silva, C. A. Camara, A. C. S. Lins et al., "Chemical composition and free radical scavenging activity of pollen loads from stingless bee Melipona subnitida Ducke," Journal of Food Composition and Analysis, vol. 19, no. 6-7, pp. 507511, 2006.

[12] B. Dineshkumar, A. Mitra, and M. Manjunatha, "Studies on the anti-diabetic and hypolipidemic potentials of mangiferin (xanthone glucoside) in streptozotocin-induced type 1 and type 2 diabetic model rats," International Journal of Advances in Pharmaceutical Sciences, vol. 1, no. 1, pp. 75-85, 2010.

[13] M. Hayakari, Y. Kondo, and H. Izumi, "A rapid and simple spectrophotometric assay of angiotensin-converting enzyme," Analytical Biochemistry, vol. 84, no. 2, pp. 361-369, 1978.

[14] E. S. Chan, B. B. Lee, P. Ravindra, and P. Denis, "Prediction models for shape and size of Ca-alginate macrobeads produced through extrusion-dripping method," Journal of Colloid and Interface Science, vol. 338, no. 1, pp. 63-72, 2009.

[15] T. Higuchi, "Mechanism of sustained action medication: theoretical analysis of rate of release of solid drugs dispersed in solid matrices," Journal of Pharmaceutical Science, vol. 52, no. 12, pp. 1145-1148, 1963.

[16] R. W. Korsmeyer, R. Gurny, E. Doelker, P. Buri, and N. A. Peppas, "Mechanisms of solute release from porous hydrophilic polymers," International Journal of Pharmaceutics, vol. 15, no. 1, pp. 25-35, 1983.

[17] P. L. Ritger and N. A. Peppas, "A simple equation for description of solute release. I. Fickian and non-Fickian release from non-swellable devices in the form of slabs, spheres, cylinders or discs," Journal of Controlled Release, vol. 5, no. 1, pp. 23-36, 1987.

[18] M. A. Kamaruddin, M. S. Yusoff, and H. A. Aziz, "Preparation and characterization of alginate beads by drop weight," International Journal of Technology, vol. 5, no. 2, pp. 121-132, 2014.

[19] K. D. Rassis, S. I. Saduy, and A. Nussinovitch, "Collapse, shrinkage and structural changes in dried alginate gels containing fillers," Food Hydrocolloids, vol. 16, no. 2, pp. 139-151, 2002.

[20] A. N. Martin and P. J. Sinko, Martin's Physical Pharmacy and Pharmaceutical Sciences: Physical Chemical and Biopharmaceutical Principles in the Pharmaceutical Sciences, Lippincott Williams and Wilkins, Philadelphia, PA, USA, 2006.

[21] A. Kikuchi, M. Hawabuchi, A. Watanabe, M. Sugihara, Y. Sakurai, and T. Okano, "Effect of $\mathrm{Ca}^{2+}$-alginate gel dissolution on release of dextran with different molecular weights," Journal of Controlled Release, vol. 58, no. 1, pp. 21-28, 1999.

[22] A. Belscak-Cvitanovic, R. Stojanovic, V. Manojlovic et al., "Encapsulation of phenolic antioxidants from medicinal plant extracts in alginate-chitosan system with ascorbic acid by electrostatic extrusion," Food Research International, vol. 44, no. 4, pp. 1094-1101, 2011.

[23] J. M. C. Puguan, X. Yu, and H. Kim, "Diffusion characteristics of different molecular weight solutes in $\mathrm{Ca}$-alginate gel beads," Colloids and Surfaces A: Physicochemical and Engineering Aspects, vol. 469, pp. 158-165, 2015.

[24] M. G. Ferruzzi, V. Bohm, P. D. Courtney, and S. J. Schwartz, "Antioxidant and antimutagenic activity of dietary chlorophyll derivatives determined by radical scavenging and bacterial reverse mutagenesis assays," Journal of Food Science, vol. 67, no. 7, pp. 2589-2595, 2002.

[25] N. I. Krinsky and E. J. Johnson, "Carotenoid actions and their relation to health and disease," Molecular Aspects of Medicine, vol. 26, no. 6, pp. 459-516, 2005.

[26] L. De Oliveira, M. Veras de Carvalho, and L. Melo, "Health promoting and sensory properties of phenolic compounds in food," Revista Ceres Viçosa, vol. 61, pp. 764-779, 2014.

[27] J. Bernal, J. Mendiola, E. Ibáñez, and A. Cifuentes, “Advanced analysis of nutraceuticals," Journal of Pharmaceutical and Biomedical Analysis, vol. 55, no. 4, pp. 758-774, 2011. 


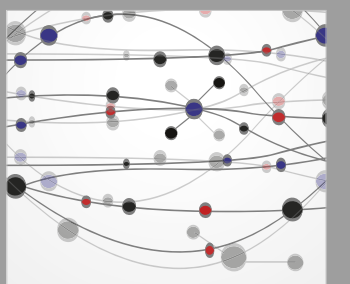

The Scientific World Journal
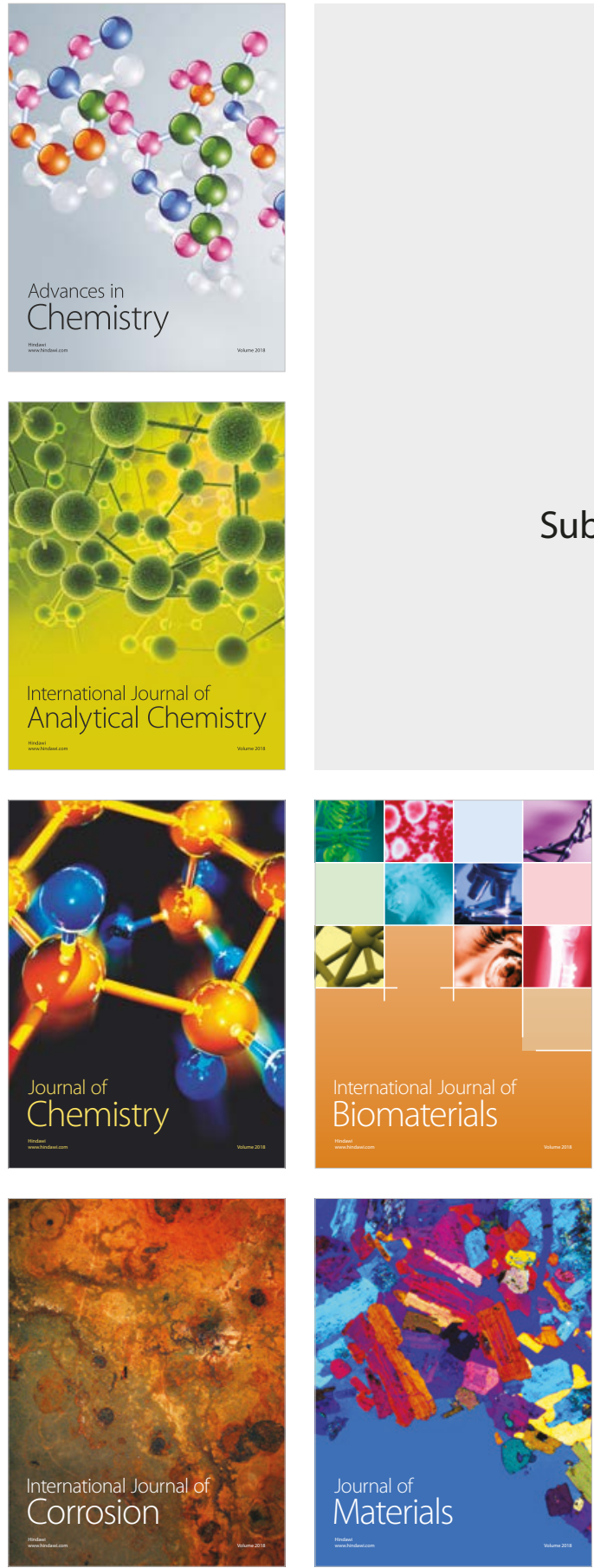

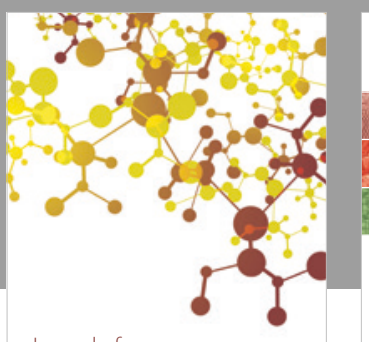

Journal of

Applied Chemistry
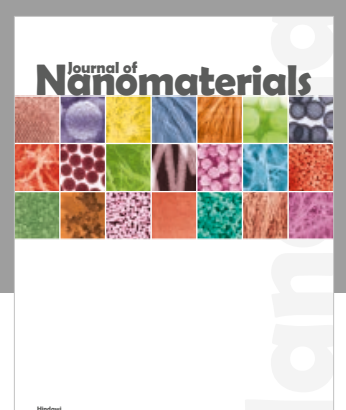

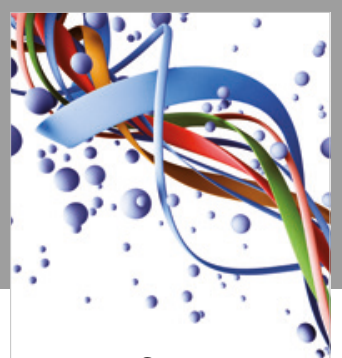

Scientifica

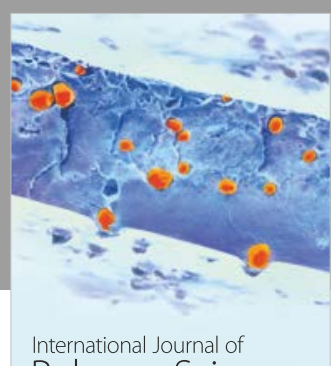

Polymer Science

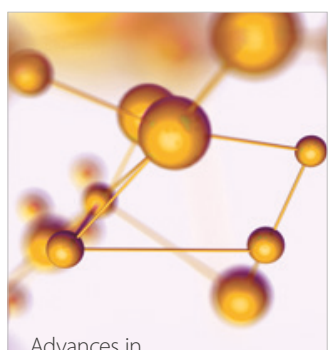

Physical Chemistry
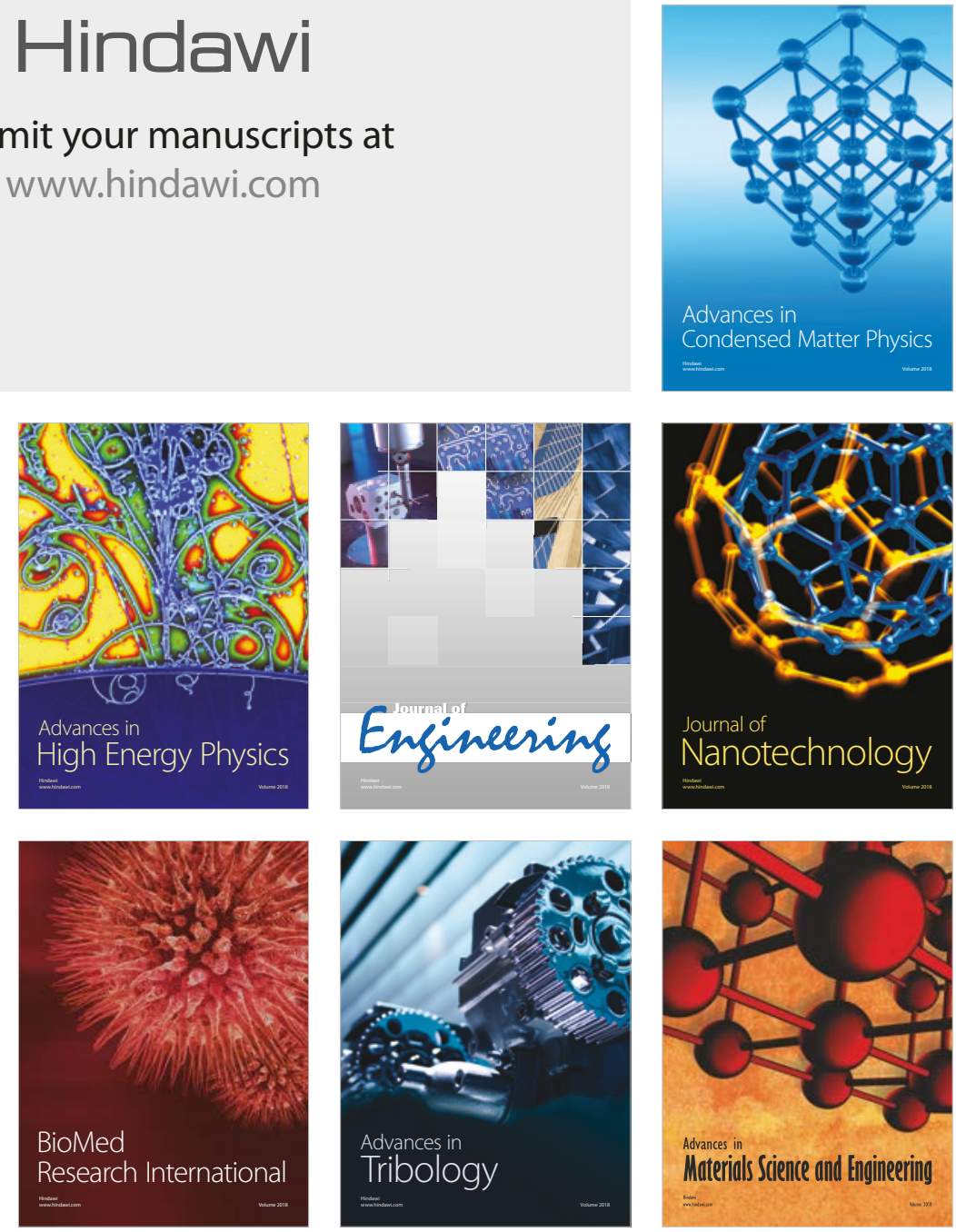